ments of some patients, a twist of the specialist's sound has sometimes rectified a long overlooked twist of the womb. Such tales recall to my memory the boasted achievements of the magician's wand, or the magic touch of the bone-setter's art. I cannot say that this speedy rectification of uterine twists accords with my experience, even when the sound and pessary have been used under the guidance of the respected leaders of the obstetric art. The world has been accustomed to see and to smile at the blindness which often prevents a specialist from finding any other ailment in a consultant than in his favourite organ. Let us hope that it may have been only this form of amiable blindness which afflicted the gentlemen connected with the cases which I have enumerated. In conclusion, there is one thing which I think a specialist should do in such cases : having mentioned the word displacement, he ought also to be particular to explain that, although the ordinary medical attendant may not have said there was displacement, yet that he must have been aware of its existence, as the displacement is generally only one of the symptoms of the disease of the womb afflicting the patient. In disease of the hip-joint, with resulting dislocation on to the ilium, a consulting surgeon would never dismiss the patient under the idea that his ordinary medical attendant had overlooked the dislocation, and that it was simply a case of dislocation of the hip-joint.

\section{ON THE TREATMENT OF STRICTURE OF THE URETHRA.}

BY W. F. TEEVAN, B.A., F.R.C.S., Surgeon to the West London Hospital, etc.

As the report of the paper which I read before the Medical Society was but an abstract, I am happy to supply any information that Mr. Swain may desire. That gentleman states that the French flexible instruments are "very perishable, and, after a few usings, become dangerous." I presume his remarks apply to the English-made instruments, which, like most imitations, are bad. I have tried the French bougies and catheters made and sold in England, and have found them to bear out Mr. Swain's statements regarding them. For many years I have daily used the French instruments, which I import direct from M. Lasserre, 5, Avenue Victoria, Paris; and I can hardly say too much in their praise. They are most durable, and never crack or break. The only care they require is to be kept well oiled, in a warm room. $\mathrm{Mr}$. Swain complains that " in old, long, gristly strictures, they double up and refuse to pass onwards." At the discussion at the Clinical Society, a similar complaint was made by a surgeon regarding these instruments; and I cannot do better than give Mr. Maunder's answer : "With skill and care, the incident referred to would be obviated." If any attempt be made to force onwards the very slender filiform bougies, they will double up; but if they be insinuated with extreme delicacy, and withdrawn a quarter of an inch for every half-inch of progress made, they will rarely fail to penetrate the most desperate strictures. In some cases of hard gristly strictures, I use metallic hougies of the same shape as the elastic bourie olivaire; but, whether I employ metal or elastic bougies, I dilate the patient's urethra up to No. 30 French gauge, considering that No. 25 ought to be the minimum to aspire to. I would here observe that No. 12 English is equal to about No. 20 of the French gauge. Sometimes the narrowness of the meatus externus interferes with dilatation: I accordingly freeze the part and slightly incise it, which procedure affords ample room for the passage onwards of the largest instrument.

Mr. Swain says he "cannot understand how external urethrotomy can be advocated in preference to any other plan of curing stricture." I only perform that operation when, after repeated trials, I fail to pass the smallest instrument. I have consequently to divide the stricture, and work my way into the bladder without any guide. This operation is not Syme's, which requires a staff to be passed through the stricture for a guide; but the old French operation evolved from "la boutonnière". For those limited cases of stricture which can only be dilated to a certain point, or, if dilated, speedily contract again, I recommend the "subcutaneous division" originated by Dr. Henry Dick, to whose writings and those of M. Auguste Mercier I am much indebted, and would refer the readers of the JOURNAL for information.

All statistics published regarding forcible rupture are nearly useless, as they omit to state what was the condition of the urethra immediately before the operation and three years afterwards.

If there be a point in the pathology of sticture on which all surgeons are agreed, it is that the worst of all strictures is the traumaticthat produced by lacerating the mucous membrane; whereas a clean cut into the urethra, as in lithotomy, is not followed by any contrac- tion. Now, if a stricture be split up, we are, by lacerating the mucous membrane, laying the seeds of a traumatic stricture, in addition to the organic one already existing. The cases related by $\mathrm{Mr}$ Timothy Holmes and Mr. W. Stokes show that, if the urethra be examined a few hours after death following forcible rupture, the mucous membrane is found lacerated.

$\mathrm{Mr}$. Swain states that the fatality following forcible rupture must be explained "by its having been used in cases where renal disease or some other unhappy complication rendered any treatment perilous." Now one of the great and inestimable advantages possessed by gradual dilatation, as carried out by the French flexible bougies, is, that the method is absolutely free from danger, no death ever having followed its use anywhere, so far as I can ascertain; whereas forcible rupture would seem to be attended with serious risks to life, and followed by other unfortunate sequences. I know of twenty-one deaths following forcible rupture in the hands of hospital surgeons, plus several more which have occurred at a certain hospital. One hospital surgeon, who had discontinued forcible rupture, told me that, in the last case in which he employed it, the patient was attacked with retention of urine; another hospital surgeon informed me, a few days ago, that in one day he had no less than three cases of bad recurrent strictures after forcible rupture by an eminent surgeon; and a third hospital surgeon showed me a calculus which had formed on the clot after forcible rupture, and said that he had cured by gradual dilatation with the olivary bougie a case which had been twice split within three months, the second operation being followed by such severe hæmorrhage that an instrument had to be tied in for twenty-four hours, which procedure was attended by abscess and fistula in perinceo.

I have but little hope of surgeons agreeing as to which is the best method of treating stricture, until such time as they are all enabled to summon up sufficient moral courage to publish the unsuccessful results attending their operations.

\section{CASES ILLUSTRATING THE OCCURRENCE OF ABNORMAL ERUPTIONS IN SMALL-POX.}

BY FREDERICK POLLARD, M.B.Lond.,

Resident Medical Officer to the St. Pancras and Northern Dispensary.

IN addition to its own specific rash, small-pox is occasionally attended by other eruptions, the occurrence of which may considerably increase the difficulties of diagnosis in the early stages; while in other instances they may have an important bearing on prognosis. These points are severally illustrated by the following two cases.

CASE I. - William M., aged $\mathrm{I}_{7}$, was first seen on the third day of illness. He had then a temperature of 106 deg., no eruption, severe frontal headache, and a thickly coated tongue. He had been sick, but had had no particular back-ache. He had been vaccinated in infancy, and showed two good cicatrices. Next day (the 4th) there was a copious crimson mottled eruption all over the face, body, and arms, occurring chiefly in round spots of the size of a threepenny-piece, in some parts discrete, but mostly running together in mottled patches. The spots were of the colour of measles-eruption, not at all elevated, and fading entirely on pressure. There were also a few slightly elevated papules about the face ; temperature still $106 \mathrm{deg}$. The patient chiefly complained of headache and insomnia. I ordered a dose of chloral at bed-time. Next day (the 5th), the temperature had sunk to roo deg. The crimson rash had entirely disappeared; the variolous papules on the face remaining, and being more elevated and shotty than on the previous day. The patient had slept a good deal, and the headache was better. He was ordered to the Hampstead Hospital, where he has progressed favourably, and is now convalescent.

CASE II. - Jessie T., aged 5, was first seen on the fourth day of illness. On the first and second days, the symptoms had been fever, sickness, and general pains; on the third, the purpurous eruption appeared. When seen (fourth day), she was found to have a temperature of I05 deg., pulse 184 , respirations 84 . There were a large number of purpurous spots from the size of a threepenny-piece downwards on the arms, body, and legs; they were round or oval, with distinct margins, and quite permanent on pressure. There were also two or three marks resembling bruises. In addition to this eruption, there were a few not very characteristic papules about the face ; but the friends were not sure whether these appeared on the third or fourth day, as they had been overlooked, in consequence of the dark blue spots attracting more attention. The child was very restless, continually tossing about, and could not be got to answer questions. There was no evidence of hæmorrhage from any of the mucous membranes, nor of any thoracic mischief. Death occurred the same evening. 